\title{
Creative Education, Globalization and Social Imaginary
}

\author{
Ponsan Rojanapanich ${ }^{1}$, Nattavud Pimpa ${ }^{2}$ \\ ${ }^{1}$ Rajamangala University of Technology, Nakhon Pathom, Thailand; \\ ${ }^{2}$ School of Management, RMIT University, Melbourne, Australia. \\ Email: ponsanphd@yahoo.com, nattavud.pimpa@rmit.edu.au \\ Received September 12 $2^{\text {th }}, 2011$; revised October 12 ${ }^{\text {th }}, 2011$; accepted October $24^{\text {th }}, 2011$.
}

\begin{abstract}
The concept of creativity in education is linked with a range of social factors. By examining the relationship among social, educational factors and creativity among students in Thailand, this study proposes that educators and policy makers must understand various global factors that affect contemporary education. They include changes in contemporary politics, culture and communication in the global education contexts. The study confirms that modern cultural factors and concept of gender are marked as key predictors of the development of creativity among young Thai students. It is reported in this study that various facets of globalization also promote creativity and imagination among young Thais. Young Thai students in this study are, in fact, willing to participate in many creative educational and social activities.
\end{abstract}

Keywords: Creativity, Social Imaginary, Education Policy, Globalization, Thai Studies, Higher Education

\section{Introduction}

Creativity in education is one of the critical themes among researchers from various disciplines. Although globalization and a faster rate of innovation are two of the most frequently mentioned trends in creative education (Frese, 2000; Rank et al., 2004), little attention has been devoted to research in social and policy issues related to creative thinking in education and society. Previous studies in education are replete with descriptions of creativity and creative thinking. They, however, are not successful in identifying the process of creative thinking in educational management and policy area (Rank et al., 2004). From the overall perspectives of research in creativity and creative education, Dacey (1999: p. 321) suggested that modern creativity research has developed across a range of disciplines as "psychological and contextual influences received more recognition". Furthermore, creativity should not be seen purely in terms of novel ideas but that it is intrinsically bound with the teaching of academic disciplines (Rowlands, 2011).

Some studies on creative education and training (i.e. West \& Farr, 1990; Rank et al., 2004; Xu \& Rickards, 2007) pointed that, by encouraging learners to think analytically about their own learning processes, combining global and local factors in the learning processes, and providing general and specific strategies for a wide variety of learning environments, learners may be able to take greater control of their own thinking and learning in various aspects. It is, therefore, believed that students who are taught in this way have been more readily able to attribute their successes and failures to factors which they can themselves control. Thus, they are increasingly autonomous as creative learners (Kratzer et al., 2006). Carney-Strahler (2011) suggested that creativity and creative learning can be nurtured and encouraged in various environments. For this reason, global and local factors affect the level of creativity in all societies.

Creativity in education can be influenced by various social and political factors that control the management and administration of social and governmental institutions. The conceptual development of creativity and social imaginary stems from a philosophy of human society and it emerges from feelings and thinking about life experiences and social perspectives in order to create new ways of understanding the manifestation and development of cultural life (Dacey, 1999).

As suggested by Rowlands (2011) that a truly creative idea, not one that is merely novel but innovative with respect to a background of ideas, does not come out of the void; it must rely on the insights of predecessors. From the educational philosophy, Jaworski (1994) confirms that the accumulation of global and local knowledge contribute to how students conceptualize their views to the world. It is, therefore, critical to understand global and local factors affecting creativity in education. The interactions between globalization, traditional cultures and contemporary social policy can be a site where creative education is generated for individuals and the collective.

\section{Social Imaginary and Creativity in Modern Society}

Social imaginaries have long been an important focus of social research since the 1930 s, though arguably earlier, growing out of theorizing by the Frankfurt School and its antecedents (Kellner, 1992). The concept is about how the imagination can be used in the everyday lives of people in order to effect social change (Rojanapanich, 2010). Some argues that this concept is also about bringing creative and possibilities into the sphere of everyday life in the globalized world. Appadurai (1999) also employed the concept in a discussion of globalization, modernity and quotidian creativity. In his discussion, Appadurai (1999) claimed that globalization is present in newer positions for the imagination in social life. These positions are described as the social imaginary, a form of daily activity directed at creating possibilities for societal change linked to globalization. From these positions, a social imaginary is about how imagination can be used in the everyday lives of people in a society to do things that will change human society.

In support of those arguments, Rizvi (2006: p. 193) observed that "it involves processes through which people engage with ordinary life, consider options and make decisions, now in new forms of collaborations that are no longer confined to local communities but span across national boundaries".

Globalization embraces many of the major issues in con- 
temporary societies. Its meaning is deeply and widely contested and it has highly uneven outcomes (Wade, 2004). Globalization of creativity is among new important ways to understand change in modern human society (Rojanapanich, 2010). Some social scientists attempt to identify the effects of globalization, imaginary and creativity by focusing on one's imagination and the way they are educated (Appadurai, 1999). According to Appadurai "globalization is not simply the name for a new epoch in the history of capital or in the biography of the nation state". He cited that it (globalization) involves how people connect with day to day life and function effectively together in communities and in groups across social and national boundaries. It, therefore, can be presumed that various facets of globalization may affect creativity in different societies.

Previous studies in this area (i.e. Keong \& Soon, 1996) confirms that demographic factors such as age, sex, marital status and birth order may affect ability to apply creative thinking at the workplace and/or other social organizations. Yamada (1991) also confirm that resources, facilities, personal assistance and social regulations seem to affect the level of team and individual creativity within the organization. A study of Egyptian business organizations by Mostafa (2005) also confirms that political, social and cultural structure (i.e. being group-oriented society and high commitment to the top management) affect the way in which an individual think creatively.

Appadurai (1999) further his discussion by looking at the relationship between the knowledge of globalization and the globalization of knowledge. That is, globalization brings in a new role for the imagination in social life, rather than simply naming a distinctive period in the history of capital in the biographies of nation states. To him, social imaginary can play a significant role in fostering social development in a country. He confirmed that "social reform, culture shaped by globalization, improvements in the education system, and other initiatives directed at improving the quality of human life all require creative innovation in social visions".

In this aspect, social imaginary and creativity are well-linked as a method to understand how globalization shapes culture to improve society and everyday life. However, as Dickens (2004) recently noted, globalization is problematic and this applies to its role in the social imaginary. Although globalization is linked to and embraces many of the major issues in creative education, its meaning is deeply and widely contested and it has highly uneven outcomes (Giddens, 2003). This also needs to be taken into account in theorizing the role it plays in the (re)construction of the social imagination (Held \& McGrew, 2003).

\section{Creativity and Thai Education}

Creativity is one of the key concepts affecting education reform in Thailand (Pimpa \& Rojanapanich, 2009; Rojanapanich, 2010). Traditionally, Thailand has been a subsistence economy where people have produced what was necessary for their own living (Phongvivat, 2002). Thai identity stems from the Buddhist worldview where "the aim of Buddhism is not to shape life in the world, but to teach liberation, release from the world. The Buddhist attempts to attain inner peace (Nibbana) through self-development is understood as an absolutely personal performance of the single individual" (Premasiri, 1996: p. 14).

Thai culture evolves largely around Buddhism and respect for seniority, whether in terms of age, status or wealth. Notwithstanding the respect given to seniority, Buddhist monks receive absolute deference and it is common to see healthy young monks sitting on buses while elderly passengers stand (Yukongdi, 2001). Seniority has different forms: younger people respect elders, the poor look up to the rich, and common citizens defer to politicians and high ranking military personnel (Mulder, 1996). Hofstede (1991) also confirms that Thai society is collectivistic and high in power distance. However, the understanding about the relationship between creativity and collectivism in Thailand remains unclear (Rojanapanich, 2010).

In an earlier work, Mulder (1996) observed that Thai people's connection to traditional ways of thinking limits the possibility for individual imagination. Supported by these ideas, Thanasankit (2002) stated that young Thai people believe in expert decision - that is, they have a strong respect for authority - rather than public decision which emanates from Western culture where knowledge is validated through a social process. Thai children, accordingly, are brought up to believe in the virtue of obeying parents, teachers and other adults. Thus it could be argued that a characteristic of Thai culture is that young people conform to older people's patterns regardless of whether they are right or wrong; it might be questioned if Thai people are to create creativity or to adapt to the modern world?

Global changes in culture, economy, politics and communication technology tend to affect various aspects of thinking and behaviors among younger generation worldwide. The young generation of Thailand has been affected by such changes. Education reform in Thailand since 2005 has focused on promoting creativity and modern thinking among students (MOE, 2006). We, therefore, need to understand the concept of creativity among young generation in the Thai higher education system. Having established the relationship among globalization, social imaginary and creativity, the key question for this study is:

What are the relationships among social imaginary, globalization factors and creativity in the perceptions of young Thai University students?

\section{Methodology}

The purpose of this paper is to investigate the social imaginary in Thai society through examining the relationships of globalization and cultural dimensions on social creativity with a focus on the opinions of young Thai University students. University students were selected as the major subject for this study, due to the government policies on education reform. This group has been in the process of the reform that focuses on the development of creativity in higher education (MOE, 2006).

Since the focus of this study, the social imaginary concept, is complicated, the research sample groups include students who were familiar with sociological theories. In this project, the researchers was concerned with attitudes held by Thai undergraduate students from the Faculty of Sociology and Anthropology at Thammasart University (a prominent social sciences public university), and social science major students in the Faculty of Liberal Arts at Sripatum University, a liberal arts private university. Questionnaire surveys were conducted with students from both institutions.

In this study, two groups of variable are formed base on literature in social imaginary and creativity. Social imaginary with creativity is the dependent variable, four globalization factors (economic, culture, information and political globalization) and Hofstede's cultural dimensions (power distance, uncertainty avoidance, masculinity, individualism and long term 
orientation) are key independent variables.

A target sample of 600 students from both universities was calculated using a sampling size from Krejcie and Morgan's (1970) sampling technique. A total of 223 students were achieved in this study. In the questionnaires, topics covered the students' attitudes and perceptions towards studying in social science programs, the goals of their careers, the impact of globalization and cultural dimensions in their lives, and also the possibility of the development social imaginary and creative concepts that could be applied in Thai society. The questionnaire was first developed in English and then translated into Thai with assistance from the Chalermprakiet Center of Translation and Interpretation in the Faculty of Arts at Chulalongkorn University.

\section{Results}

\section{Globalization, Culture and Social Imaginary in the Thai Society}

The results in Table 1 indicate that the participants agree that cultural globalization $(\mathrm{M}=4.85, \mathrm{SD}=.807)$ is the strongest influence in Thai society compared to the other forms of globalization. This is followed by economic globalization $(\mathrm{M}=4.70$, $\mathrm{SD}=.886)$, communication globalization $(\mathrm{M}=4.52$, $\mathrm{SD}$ $=.699$ ). The least powerful factor among the four globalization factors was the political globalization $(\mathrm{M}=4.01, \mathrm{SD}=.762)$.

As mentioned, the research project has employed Hofstede's (1991) cultural dimensions: power distance, uncertainty avoidance, masculinity, individualism, and long term orientation. The questionnaire also includes questions about attitudes to identify association among these dimensions. The results in Table 2 show high score for long term orientation $(\mathrm{M}=4.99$, $\mathrm{SD}=.75$ ). The students are in strong agreement that these two cultural dimensions are very significant factors in Thai society as they relate to social creativity and the social imaginary.

These two dimensions also have the smallest spread, adding to the strength of that view. Power distance $(\mathrm{M}=3.56$, SD $=.89)$, uncertainty avoidance $(\mathrm{M}=4.04, \mathrm{SD}=.84)$ and mas-

Table 1.

Globalization effects in Thai society.

\begin{tabular}{ccc}
\hline Variables & M & SD \\
\hline Economic Globalization & 4.70 & .88 \\
Culture Globalization & 4.85 & .81 \\
Communication Globalization & 4.52 & .70 \\
Political Globalization & 4.01 & .76 \\
\hline
\end{tabular}

Table 2.

Culture dimension in the Thai context.

\begin{tabular}{ccc}
\hline Variables & M & SD \\
\hline Power Distance & 3.56 & .89 \\
Uncertainty Avoidance & 4.04 & .84 \\
Masculinity & 4.02 & .82 \\
Individualism & 4.98 & .79 \\
Long-Term Orientation & 4.99 & .75 \\
\hline
\end{tabular}

culinity (or gender orientation) $(\mathrm{M}=4.02, \mathrm{SD}=.82)$ present lower results and show up as neutral in compassion.

Finally, the results on social imaginary and creativity among Thai students show that Thai students support creativity at all levels of society present in agreement. Items about families, creativity and society supporting young people to be creative reflect the strongest levels of agreement. The mean score for the social imaginary and creativity scale is $4.71(\mathrm{SD}=.86)$, which is considered high. An ANOVA test was performed to analyze whether globalization and cultural dimensions were significant predictors of social imaginary and creativity in Thai society. Since the $r$ value of .00 was less than .05 , the researchers assume that globalization and cultural dimensions are significant predictors of social imaginary in Thai society.

\section{The Relationship among Globalization, Social Imaginary, Creativity and Thai Culture}

The relationship among globalization and cultural dimensions on social imaginary (and creativity) was tested using multiple regression analysis. Preliminary analyses were conducted to ensure no violation of the assumption of normality, linearity, and multi-colinearity. The total variance explained by the model as a whole was $56 \%,(\mathrm{~F}(9,211)=29.82, p<.01)$ as presented in Table 3.

An ANOVA test was performed to analyze whether globalization and cultural dimensions were significant predictors of social imaginary and creativity in Thai society. Since the $r$ value of .00 was less than .05 , the researchers assume that globalization and cultural dimensions are significant predictors of social imaginary in Thai society.

In the final model, as presented in Table 4, seven independent variables were found to be statistically significant. Three factors from globalization (culture, communication, and political globalization) and four factors from cultural dimensions (power, gender, group, and goal orientations) significantly contributed to social imaginary and creativity among the young Thai students in this study. The relationship can be explained by the following regression model. This model identifies positive impact from cultural globalization, political globalization, gender orientation, group orientation, and goal orientation on social imaginary for Thai students in this study.

Based on the analyses, it was found that seven independent variables (individualism, culture globalization, masculinity, political globalization, long term orientation, uncertainty avoidance and economic globalization) were positively significant to the social imaginary in Thailand. However, two of the variables (communication globalization and power distance) were found to be negatively significant to the social imaginary in Thailand.

The regression model indicates various globalization and cultural dimensions as positively contributing to the social imaginary and creativity. Individualism is the strongest predictor that is positively significant to social imaginary and creativity $(p<.01, \beta=.264)$. The students in this study believed that the concept of individualism is important to encourage social creativity. More importantly, it may predict personal contributors to new ideas and also help them to respond to the social change more than other dimensions.

Predicted social imaginary $=0.225$ culture globalization; -0.212 communication globalization; +0.201 political globalization; -0.116 power distance; +0.221 masculinity;

+0.264 individualism; +0.171 long term orientation 
Table 3.

Regression model.

\begin{tabular}{cccccc}
\hline Model & df & Sum of Squares & Mean Square & F & p \\
\hline Regression & 9 & 91.88 & 10.21 & $29.82^{* *}$ & .00 \\
Residual & 211 & 72.23 & .34 & & \\
Total & 220 & 164.12 & & & \\
\hline
\end{tabular}

$\mathrm{R}=.75, \mathrm{R}^{2}=.56, \mathrm{~F}=29.82$

Table 4.

Regression model.

\begin{tabular}{cccccc}
\hline Variable & \multicolumn{1}{l}{ Unstandardized Coefficients } & Standardized Coefficients & t & p \\
\hline EGS & $\beta$ & Std. Error & B & & \\
CGS & .103 & .063 & .106 & 3.640 & .10 \\
CMGS & .225 & .065 & .210 & $-3.44^{* *}$ & .00 \\
PGS & -.212 & .066 & -.172 & $-3.236^{* *}$ & .00 \\
PDI & .201 & .077 & .177 & $2.595^{* *}$ & .01 \\
UAI & -.116 & .058 & -.120 & -1.990 & .06 \\
MAS & .114 & .069 & .111 & 1.638 & .10 \\
IDV & .221 & .065 & .211 & $3.415^{* *}$ & .00 \\
LTO & .264 & .064 & .243 & $4.160^{* *}$ & .00 \\
\hline
\end{tabular}

Note: EGS = economic globalization; CGS = culture globalization; $\mathrm{CMGS}=$ communication globalization; $\mathrm{PGS}=$ political globalization, IDV = individualism; PDI = power distance; MAS = masculinity; UAI = uncertainty avoidance; LTO = long-term orientation (or Confucian dynamism) (Sources: Hofstede, 2003)

The second and third significant predictors to social imaginary were cultural globalization $(p<.01, \beta=.225)$, and the masculinity dimension $(p<.01, \beta=.221)$. Culture and gender play significant roles in minds of participants in this study in the creation of the social imaginary. There was also a positive relationship between political globalization and social imaginary $(p<.01, \beta=.201)$.

Long term orientation $(p<.01, \beta=.171)$ was found to be less influential, but still significant to the development process of the social imaginary. The least significant factor contributing to the social imaginary was uncertainty avoidance $(p<.01, \beta$ $=.171)$. The researchers found that power distance $(p<.01, \beta=$ -.212), was significant in contributing to development of the social imaginary and creativity, but in a negative aspect. This may be interpreted on meaning the Thai university students see social hierarchies as a negative factor in developing creativity in Thai society. That is, as the influence of hierarchies increase, the chances of new ideas may decrease.

Economic globalization does not significantly contribute to the concept of social imaginary and creativity. Furthermore, uncertainty avoidance is insignificant in its contribution to the social imaginary concept. Although most $\beta$ values identify statistical significance, there are some limitations to interpretation in this model. Firstly, the researcher only selected some globalization factors from the literature to test their relationship with social imaginary. Thus, it should be noted that factors other than globalization may affect the social imaginary. Secondly, given positive relationship between all variables, some of the regression is highly negative when controlled by the influence of other variables. The interpretation contributions of some variables (i.e. communication globalization and power distance) are negative because their influence is indirect, expressed though their relationship with other variables.

\section{Implications of the Study}

The findings revealed some critical points and provide an invaluable understanding concerning the importance of social imaginary and creativity in Thai society. In particular, the results suggest that globalization has had a considerable impact on creativity among Thai students. The findings indicate that in regard to cultural dimensions, power distance is an obvious factor on the perception of Thai students being the "young ones" who need to respect the "more powerful" people in society. They seem to accept this about less powerful members of institutions, like themselves, and expect and accept that power is distributed unequally. Clearly, those with power in society can stimulate creativity in education among young Thais.

The students in this study may be too afraid to express their doubts and disagreements with their teachers or parents. This can be one of the factors that may negatively contribute to the various levels of social creativity among the young Thai citizens. Criticism may create conflict which does not go with the idea of social harmony in Thai society.

With regards to the relationship among social imaginary, globalization, and cultural dimensions, the results indicate 
strong positive relationship among various globalization and cultural dimension factors. The findings suggest that in terms of the correlation among factors, globalization affects various aspects of Thai society and all of them correlate to each other. It is inevitable not to integrate the political, economic, communication, and cultural impacts in the interpretation of globalization effects in contemporary Thailand.

In the analyses, three factors of individualism, cultural globalization and masculinity were evident as predictors of the development of the social imaginary and creativity in Thailand. Power distance was negatively correlated to the development of social imaginaries, whilst uncertainty avoidance and economic globalization had no significant effect.

The result from the study was somewhat surprising because initially, following the literature review, it is believed that economic globalization to be demonstrably beneficial as the idea of economic competition between the countries motivates the growth of new ideas amongst people in society. In view of that, society would be motivated to develop new sets of social knowledge or creativity in response to the effects of globalization. For instance, the "modernization argument holds that economic development in Thailand [has] created a substantial, well-educated urban middle class people that wanted accountable democratic government" (Deveney, 2005), and it might be expected that the changed social location of university students may have been more strongly reflected in the results about economic globalization as it linked to the development of new social imaginaries and creativity.

This study also presents information technology globalization as a significant negative predictor to the social imaginary $(p<.01, \beta=-.212)$. Based on this result, globalization of information technology could have a significant impact on social imaginary, but in negative ways, meaning that it was received by people unexpectedly and that they may need to counteract it in the development of social imaginaries. That is to say, information technology is important, but not directly to the development of the social imaginary.

This seemingly contradictory position is also reflected in views of others. While Sinlarat (2005: p. 266) argued that "the growth of globalization and the development of the internet has made the transfer of knowledge seemingly limitless, countless, and timeless, creative learning occurs instantly and everywhere", in contrast to these comments Chareonwongsak (2002), in discussing the impact of global technology in our lives, says that "lifestyle and human social behavior are responding much as they did to all other waves in human history-with great difficulty and, in unexpected ways".

\section{Conclusion}

The results from this study may be interpreted as saying that Thai students consider technological, social and communicational factors contributes to creativity. In regards to points on information technology and global media playing an essential role in influencing Thai people's way of thinking, this study confirmed that Thai university students did not believe that global technology would heavily impact on their lives and creativity. They considered technology as a natural element and a part of the taken for granted (ordinary) life. Conversely, older people may consider the concept of technological globalization as more complicated. The gap between the perceptions of these two groups becomes clearer as we continue to investigate globalization.
A core argument of this paper is that the positive benefits of globalization must be reflected in creative education, that is, in curricula and in teaching and learning methods. Moreover, globalization has been significant in encouraging the knowledge and imagination for young people and such results have shown that Thai students are in fact willing to participate in many creative activities.

Finally, while there is a large proportion of research on creativity in education and organizations in the West, little is known about the context of creativity in South East Asia. Future research should explore issues that ignite curiosity, adventurousness, and new ways of thinking within the diverse south East Asian cultural context.

\section{Acknowledgements}

The authors would like to acknowledge support from Associate Professor Geoff Shacklock from the School of Education, RMIT University for his ideas for this research.

\section{References}

Appadurai, A. (1999). Globalization and the research imagination. CA: Blackwell Publishers.

Carney-Strahler, B. (2011). Wikis: Promoting collaborative literacy through affordable technology in content-area classrooms. Creative Education, 2, 76-82.

Chareonwongsak, K. (2002). Globalization and technology: How will they change society? Technology in Society, 24, 191-206. doi:10.1016/S0160-791X(02)00004-0

Dacey, J. (1999). Concepts of creativity: A history. In M. A. Runco and S. R. Pritzker (Eds.), Encyclopedia of creativity. CA: Academic Press.

Deveney, B. (2005). An investigation into aspects of Thai culture and its impact on Thai students in an international school in Thailand. Journal of Research in International Education, 4, 153-171. doi: $10.1177 / 1475240905054388$

Eisenberg, E. M., \& Goodall, H. L. (2001). Organizational communication: Balancing creativity and constraint. New York: St. Martin's Press.

Frese, M. (2000). The changing nature of work. In N. Chmiel (Ed.), Introduction to work and organizational psychology. Oxford: Blackwell.

Giddens, A. (2003). The globalizing of modernity. In D. Held and A. McGrew (Eds.), The global transformations reader (2nd ed.). London: Polity.

Held, D., \& McGrew, A. (2003). The great globalization debate: An introduction. In D. Held and A. McGrew (Eds.), The global transformations reader (2nd ed.). London: Polity.

Hofstede, G. (1991). Cultures and organizations: Software of the mind. Madenhead: McGraw-Hill Books.

Kellner, D. (1992). Critical theory, Marxism and modernity. Baltimore: The Johns Hopkins University Press.

Keong, L. C., \& Soon, L. G. (1996). Factors affecting managers and executives' attitude towards creativity training. Research and Practice in Human Resource Management, 4, 67-88.

Kratzer, J., Leenders, R., \& Van Engelen, J. (2006). Team polarity and creative performance in innovation teams. Creativity and Innovation Management, 15, 96-104. doi:10.1111/j.1467-8691.2006.00372.x

Krejcie, R. V., \& Morgan, D. W. (1970). Determining sample size for research activities. Educational and Psychological Measurement, 30, 607-610.

Ministry of Education (MOE, Thailand). (2006). Education policy for academic year 2005. Bangkok: Guru Sapha Press.

Mostafa, M. (2005). Factors affecting organisational creativity and innovativeness in Egyptian business organizations: An empirical investigation. Journal of Management Development, 24, 7-33. doi:10.1108/02621710510572326

Mulder, N. (1996). Inside Thai society: Interpretation of everyday life. 
Bangkok: Pepin Press.

Phongvivat, C. (2002). Social work education in Thailand. International Social Work, 45, 293-303.

doi: $10.1177 / 0020872802045003356$

Pimpa, N., \& Rojanapanich, P. (2008). Globalization, social imaginary and education policy in Thailand. In Proceedings of the 36th Annual Conference of the Australia and New Zealand Comparative and International Education Society (pp. 45-52). Perth: Curtin University of Technology.

Premasiri, P. D. (1996). Humanization of development: A Theravada Buddhist perspective. In B. Saraswati (Ed.), Interface of culture identity development. URL (last checked 8 November 2010) http//ignca.nic.in/Is_03005.htm

Rank, J., Pace, V., \& Frese, M. (2004). Three avenues for future research on creativity, innovation and initiative. Applied Psychology: An International Review, 53, 518-528. doi:10.1111/j.1464-0597.2004.00185.x

Rizvi, F. (2006). Imagination and the globalization of educational policy research. Globalization, Societies and Education, 4, 193-205. doi:10.1080/14767720600752551

Rojanapanich, P. (2010). The social imaginary in Thai society. Ph.D.
Thesis, Melbourne: RMIT University.

Rowlands, S. (2011). Disciplinary boundaries for creativity. Creative Education, 2, 47-55. doi:10.4236/ce.2011.21007

Sinlarat, P. (2005). Changing the culture of education in Thai universities. Higher Education Policy, 18, 265-269. doi:10.1057/palgrave.hep. 8300088

Thanasankit, T. (2002). Requirements engineering exploring the influence of power and Thai values. European Journal of Information Systems, 11, 128-141. doi:10.1057/palgrave/ejis/3000423

West, A., \& Farr, L. (1990). Innovation and creativity at work: Psychological and organizational strategies. Chichester: John Wiley.

Xu, F., \& Rickards, T. (2007). Creative management: A predicted development from research into creativity and management. Creativity and Innovation Management, 16, 216-228. doi:10.1111/j.1467-8691.2007.00445.x

Yamada, K., (1991). Creativity in Japan. Leadership and Organization Development Journal, 12, 11-14.

doi:10.1108/EUM0000000001160

Yukongdi, V. (2001).Teams and TQM: A comparison between Australia and Thailand. International Journal of Quality \& Reliability Management, 18, 387-403. doi:10.1108/02656710110386789 